\title{
On decreasing inequality in health care in a cost-effective way
}

\author{
Antti Malmivaara
}

\begin{abstract}
Background: Scientific evidence indicates that access to health care services shown effective is often poorer among the disadvantaged people than among the non-disadvantaged. Advancing cost-effectiveness and equality in obtaining services shown effective are often stated as the two main objectives for health care.

Discussion: The important question is how to decrease inequality in a most cost-effective way. Some evidence indicates that effectiveness and cost-effectiveness of interventions may be high among the disadvantaged patient groups. However, the relationship between decreasing inequality and cost-effectiveness is complex and depend e.g. on clinical and health care system factors.

Summary: To expand the knowledge base for advancing equality in a cost-effective way, scientific efforts on four levels are suggested: research into ways how practitioners can provide efficient services for the disadvantaged patients, widening of scope at all levels of evidence based medicine to account also for the disadvantaged, research on quality improvement and evidence implementation, as well as benchmarking research including documentation of services among the disadvantaged.
\end{abstract}

Keywords: Benchmarking, Cost-effectiveness, Evidence based medicine, Inequality, Medical ethics, Quality improvement, Real effectiveness medicine, Socioeconomic status

\section{Background}

Inequality in health care is defined in this article as inferior access to or inferior quality (diagnostic and treatment procedures) of services shown effective (in randomised controlled trials or based on wide consensus among experts - e.g. total hip or knee replacement) among people belonging to some disadvantaged patient group. The disadvantage may be due to age, culture, education, ethnic origin, gender, occupation, place of residence, race, religion, social capital or socioeconomic status [1].

There is evidence that disadvantaged people have on average poorer access to services, and once they have an access to service they get less often treatments that have been shown effective in randomized trials, and in case they obtain these treatments the quality they receive is poorer than among people not belonging to these groups [2-5]. Partly as a consequence of poorer access and nonoptimal quality of the services, prognosis of these patients may be inferior to that of the well to do patients [6].

Correspondence: antti.malmivaara@thl.fi

Centre for Health and Social Economics, National Institute for Health and Welfare, Mannerheimintie 166, 00270 Helsinki, Finland
There is some evidence from randomized trials and systematic reviews that effectiveness of an intervention may be even high among the most disadvantaged, and that the cost-effectiveness of the intervention may be good $[7,8]$. In some cases cost-effectiveness of an intervention is better when resources are allocated to the poorest and most marginalised populations than when allocating to those doing better [9]. However, in some cases the additional cost of tailor-made interventions for the disadvantaged may be high in comparison to benefits [10]. Unfortunately, direct evidence comparing effectiveness and cost-effectiveness of a specified intervention for a particular disorder among the disadvantaged and nondisadvantaged populations is quite limited.

The horizontal equity principle of providing equal treatment for equal medical need [11] is employed in this article, but within this framework the focus is in those interventions considered effective based on scientific evidence or wide consensus among medical experts. The access in this article refers particularly to opportunities and not to utilization itself, as the latter can differ between population groups also due to reasons beyond 
the influence of the health care system [12]. The question of distribution of health across different groups of society is not considered, because the potential of health care system is limited in this respect [13]. The conceptual categories of questions regarding measurement techniques including inequity indices are not covered.

The question of whether decreasing of inequality would lower, maintain or increase overall cost-effectiveness of the health care system is not considered, and neither the efficiency/equity trade-off [14]. An unbiased assessment of each particular patient-intervention context would require a systematic review of its own.

The aim of this paper is to consider ways how to promote scientific evidence on decreasing inequality in a cost-effective manner, and how to use this evidence in advancing equality and cost-effectiveness in health care.

\section{Discussion}

How to increase scientific evidence and promote equality and cost-effectiveness

Evidence of advancing equality in a cost-effective manner could be promoted by efforts at four levels: clinical expertise, scientific evidence, quality improvement and benchmarking [15].

Firstly, there is a need for both quantitative and qualitative research on how to teach and promote know-how of health care personnel for cost-effective treatment among the disadvantaged. The know-how includes understanding of etiology, pathogenesis, diagnosis and treatment of diseases combined with practical experience and expertise on how to deal with the disease among the disadvantaged. Special expertise may be needed as e.g. cultural differences may have impact on adherence to treatment regimens. Moreover, acceptability of effective services provided by the health care system may differ across population groups, and should also be considered. In a systematic review strategies to increase treatment adherence show moderate effectiveness and cost-effectiveness [16]. The CanMeds framework aiming to advance the abilities of health care professionals to reach optimal patient outcomes can be utilized and further tested in scientific studies [17].

Secondly, scientific goals at all levels of evidence based medicine (randomized controlled trials, systematic reviews, health technology assessments, clinical guidelines) are suggested to include cost-effectiveness of interventions also among the disadvantaged. There are large deficiencies in the scientific evidence of what is the effectiveness and cost-effectiveness of interventions among the disadvantaged groups.

The exclusion criteria in randomized trials are often such that some of the disadvantaged groups will not be included and thus no effectiveness data will emerge [18]. The CONSORT guideline for reporting randomized controlled trials does not include an item on disadvantaged patient groups [19]. This poses a problem in creating new evidence applicable to the disadvantaged patient groups.

Systematic reviews have rarely considered the disadvantaged groups: only $1 \%$ of a random sample of Cochrane reviews assessed differences in effectiveness of interventions across socioeconomic or demographic factors [20]. Thus, systematic reviews currently provide very little data applicable to the disadvantaged patient groups [21]. Applaudingly, a recent recommendation on how to include these patient groups in systematic reviews has been launched [22]. Hopefully this recommendation will be widely adopted by organizations and individuals undertaking systematic reviews.

The clinical guidelines do not usually consider the disadvantaged patient groups when assessing effectiveness or safety of interventions [23]. The AGREE instrument guiding appropriate conduct of clinical guidelines does not include the disadvantaged groups [24]. An authoritative international recommendation of how to include the disadvantaged patient groups in clinical guidelines is suggested.

Thirdly, it is suggested that quality improvement and implementation science would always consider also questions concerning services for the disadvantaged. There is a need for research assessing whether treatments suggested by evidence-based guidelines are actually implemented in ordinary clinical practice throughout the population. For example, in a study utilizing the population-based South London Stroke Register, the appropriateness of treatment had improved considerably from 1995 to 2009 , but the implementation of evidence-based care was still not optimal, and there were inequalities between socioeconomic groups [2]. The optimal strategies targeted to the developed and developing countries should also be explored.

Fourthly, benchmarking of services between providers and geographical areas are suggested [25]. Optimally the benchmarking would be accompanied by scientific research on access, quality, costs and effectiveness of services for all patient groups including the disadvantaged. As the number of high quality benchmarking studies is so far small, promotion of this type of research is suggested.

\section{Summary}

High quality services are provided by competent professionals who make use of the best current scientific evidence with an aim to maximize effectiveness and minimize harm. The lost opportunities for providing effective services for the disadvantaged patient groups may lessen costeffectiveness of the health care systems as a whole, but also of any particular health care provider who fails to provide effective services for the whole population 
which it serves. Poor safety of the services provided for the disadvantaged patient groups will further decrease the cost-effectiveness of interventions. In order to decrease the equity gap when extending the scientific evidence of efficacy into effectiveness in ordinary health care settings, the equity effectiveness loop can be utilized [26].

There is a vast evidence showing widespread inequality in obtaining services shown scientifically effective, particularly in the developing countries but also in the developed ones [3]. The current relevance of advancing equality is emphasized by evidence from developed countries that socioeconomic inequality may be widening further, shown e.g. in mortality amenable to health care interventions [27].

There are certainly differences in the relationship between decreasing inequality and increasing cost-effectiveness. The association will depend on properties of the health care systems, the wealth of the society, on the degree of inequality in a particular country, and on the clinical context. The latter can be made explicit with the PICO (patient, intervention, comparator, outcome) -concept: in some diseases the cost-effectiveness of a particular intervention for the disadvantaged patients will be better, while in other cases similar or even worse than among the well to do people. In the latter cases better strategies for providing effective treatment for the disadvantaged patients may increase effectiveness [16]. In an experimental study low-income persons who had won in a lottery the Medicaid insurance for obtaining health care services were compared with those who failed to win: the persons who did win the insurance had better access and utilization of health care services and substantial improvements in mental health, but despite better diagnosis of diabetes no reduction in glycated haemoglobin levels [28]. These findings point out that access to services as such may provide only limited benefits for the disadvantaged persons.

To sum up, this paper suggests a framework for research and practice on how to allocate the limited resources in most cost-effective way encompassing also those who currently do not obtain the services shown effective. The method is suggested to be used for advancing both the ethical objectives and cost-effectiveness requirements of the health care system. Research and development activities at the four scientific and practical levels are suggested.

\section{Competing interests}

I declare that I have no conflict of interests.

\section{Acknowledgements}

This publication contains solely the views of the author.

Funding

I declare that I have received no specific funding for this article.

Received: 14 June 2013 Accepted: 13 February 2014

Published: 20 February 2014

\section{References}

1. Tugwell P, Petticrew M, Robinson V, Kristjansson E, Maxwell L, Cochrane Equity Field Editorial Team: Cochrane and Campbell collaborations and health equity. Lancet 2006, 367(9517):1128-1130.

2. Addo J, Bhalla A, Crichton S, Rudd AG, McKevitt C, Wolfe CD: Provision of acute stroke care and associated factors in a multiethnic population: prospective study with the South London Stroke Register. BMJ 2011, 342:d744.

3. Marmot M, Friel S, Bell R, Houweling TAJ, Taylor S: Closing the gap in a generation: health equity through action on the social determinants of health. Lancet 2008, 372(9650):1661-1669.

4. Forrest LF, Adams J, Wareham H, Rubin G, White M: Socioeconomic inequalities in lung cancer treatment: systematic review and meta-analysis. PLoS Med 2013, 10(2):e1001376.

5. Artuso S, Cargo M, Brown A, Daniel M: Factors influencing health care utilisation among Aboriginal cardiac patients in central Australia: a qualitative study. BMC Health Serv Res 2013, 13(83):1-13.

6. Grube MM, Koennecke HC, Walter G, Thummler J, Meisel A, Wellwood I, Heuschmann PU, on behalf of the Berlin Stroke Register: Association between socioeconomic status and functional impairment 3 months after ischemic stroke: the berlin stroke register. Stroke 2012, 43(12):3325-3330.

7. Gilman SE, Fitzmaurice GM, Bruce ML, Ten Have T, Glymour MM, Carliner H, Alexopoulos GS, Mulsant BH, Reynolds, Charles F III, Cohen A: Economic inequalities in the effectiveness of a primary care intervention for depression and suicidal ideation. Epidemiology 2013, 24(1):14-22.

8. Mayo-Wilson E, Imdad A, Herzer K, Yakoob MY, Bhutta ZA: Vitamin A supplements for preventing mortality, illness, and blindness in children aged under 5: systematic review and meta-analysis. BMJ 2011, 343:d5094.

9. Carrera C, Azrack A, Begkoyian G, Pfaffmann J, Ribaira E, O'Connell T, Doughty P, Aung KM, Prieto L, Rasanathan K, Sharkey A, Chopra M, Knippenberg R, UNICEF Equity in Child Survival, Health and Nutrition Analysis Team: The comparative cost-effectiveness of an equity-focused approach to child survival, health, and nutrition: a modelling approach. Lancet 2012, 380(9850):1341-1351.

10. NSW Centre for Overweight and Obesity: A literature review of the evidence for interventions to address overweight and obesity in adults and older Australians. 2005:1-56.

11. Wagstaff A, van Doorslaer E: Overall versus socioeconomic health inequality: a measurement framework and two empirical illustrations. Health Econ 2004, 13(3):297-301.

12. Whitehead M, Evandrou M, Haglund B, Diderichsen F: As the health divide widens in Sweden and Britain, what's happening to access to care? BMJ 1997, 315(7114):1006-1009.

13. Hernandex-Quevedo C, Papanicolas I: Conceptualizing and Comparing Equity across Nations. In Health System Performance Comparison. An Agenda for Policy, Information and Research. 1st edition. Edited by Anonymous Maidenhead. England: Open University Press; 2013.

14. Wagstaff A: Inequality aversion, health inequalities and health achievement. J Health Econ 2002, 21(4):627-641.

15. Malmivaara A: Real-effectiveness medicine-pursuing the best effectiveness in the ordinary care of patients. Ann Med 2013, 45(2):103-106.

16. Laba TL, Bleasel J, Brien JA, Cass A, Howard K, Peiris D, Redfern J, Salam A, Usherwood T, Jan S: Strategies to improve adherence to medications for cardiovascular diseases in socioeconomically disadvantaged populations: A systematic review. Int J Cardiol 2013, 167:2430-2440.

17. Frank JR, Jabbour M, Fréchette D, Marks M, Valk N, Bourgeois G (Eds): Report of the CanMEDS Phase N. Working Groups. Ottawa: The Royal College of Physicians and Surgeons of Canada; 2005.

18. Bellera C, Praud D, Petit-Moneger A, McKelvie-Sebileau P, Soubeyran P, Mathoulin-Pelissier S: Barriers to inclusion of older adults in randomised controlled clinical trials on Non-Hodgkin's lymphoma: a systematic review. Cancer Treat Rev 2013, 39:812-817.

19. Moher D, Hopewell S, Schulz KF, Montori V, Gotzsche PC, Devereaux PJ, Elbourne D, Egger M, Altman DG: CONSORT 2010 explanation and elaboration: updated guidelines for reporting parallel group randomised trials. BMJ 2010, 340:c869.

20. Welch V, Brand K, Kristjansson E, Smylie J, Wells G, Tugwell P: Systematic reviews need to consider applicability to disadvantaged populations: inter-rater agreement for a health equity plausibility algorithm. BMC Med Res Methodol 2012, 12:187-195. 
21. Tugwell P, Maxwell L, Welch V, Kristjansson E, Petticrew M, Wells G, Buchbinder R, Suarez-Almazor ME, Nowlan M, Ueffing E, Khan M, Shea B, Tsikata S: Is health equity considered in systematic reviews of the Cochrane musculoskeletal group? Arthritis Rheum-Arthritis Care Res 2008, 59(11):1603-1610.

22. Welch V, Petticrew M, Tugwell P, Moher D, O'Neill J, Waters E, White $H_{\text {, }}$ PRISMA-Equity Bellagio Grp: PRISMA-equity 2012 extension: reporting guidelines for systematic reviews with a focus on health equity. PLos Med 2012, 9(10):e1001333.

23. Berkowitz SA, Aragon K, Hines J, Seligman H, Lee S, Sarkar U: Do clinical standards for diabetes care address excess risk for hypoglycemia in vulnerable patients? A systematic review. Health Serv Res 2013, 48:1299-1310.

24. Collaboration AGREE: Development and validation of an international appraisal instrument for assessing the quality of clinical practice guidelines: the AGREE project. Qual Saf Health Care 2003, 12(1):18-23.

25. Häkkinen U, Malmivaara A: The PERFECT project: measuring performance of health care episodes [Guest editors]. Ann Med 2011, 43(Suppl1).

26. Tugwell P, de Savigny D, Hawker G, Robinson V: Applying clinical epidemiological methods to health equity: the equity effectiveness loop. BMJ 2006, 332(7537):358-361.

27. McCallum AK, Manderbacka K, Arffman M, Leyland AH, Keskimaki I: Socioeconomic differences in mortality amenable to health care among Finnish adults 1992-2003: 12 year follow up using individual level linked population register data. BMC Health Serv Res 2013, 13(1):3.

28. Baicker K, Taubman SL, Allen HL, Bernstein M, Gruber JH, Newhouse JP, Schneider EC, Wright BJ, Zaslavsky AM, Finkelstein AN, Oregon Health Study Group, Carlson M, Edlund T, Gallia C, Smith J: The Oregon experiment-effects of Medicaid on clinical outcomes. N Eng/ J Med 2013, 368(18):1713-1722.

doi:10.1186/1472-6963-14-79

Cite this article as: Malmivaara: On decreasing inequality in health

care in a cost-effective way. BMC Health Services Research 2014 14:79.

\section{Submit your next manuscript to BioMed Central and take full advantage of:}

- Convenient online submission

- Thorough peer review

- No space constraints or color figure charges

- Immediate publication on acceptance

- Inclusion in PubMed, CAS, Scopus and Google Scholar

- Research which is freely available for redistribution 